\title{
Paternal uniparental disomy for chromosome 6 causes transient neonatal diabetes
}

\author{
M L Whiteford, A Narendra, M P White, A Cooke, A G Wilkinson, K J Robertson, \\ J L Tolmie
}

\begin{abstract}
We report an infant with intrauterine growth retardation and transient neonatal diabetes who has paternal uniparental disomy for chromosome 6 . The infant was not dysmorphic and had no congenital anomalies. To our knowledge, this is the third case of paternal uniparental disomy occurring in an infant with transient neonatal diabetes, thus confirming the association.

(F Med Genet 1997;34:167-168)
\end{abstract}

Keywords: paternal uniparental disomy; chromosome 6; transient neonatal diabetes.

In 1995 , Temple et al ${ }^{1}$ reported the association between transient neonatal diabetes and paternal uniparental disomy for chromosome 6 (UPD6) in two unrelated patients. UPD6 had been reported previously in a patient with methylmalonic acidaemia and neonatal diabetes, ${ }^{2}$ but this patient died at the age of 16 days so it is uncertain that the diabetes was transient. We now report a further patient with paternal UPD6 and transient neonatal diabetes.

The male infant, born at term, was noted to be growth retarded: weight $1800 \mathrm{~g}$ ( $<3 \mathrm{rd}$ centile), length $44.5 \mathrm{~cm}$ ( $3 \mathrm{rd}$ centile), and OFC $31.9 \mathrm{~cm}$ (3rd centile). He was not dysmorphic and general examination was unremarkable. Blood glucose monitoring was started and at 20 hours of age his true blood glucose was 18.8 $\mathrm{mmol} / \mathrm{l}$. Urea and electrolyte and blood gas measurements were normal. Urine analysis showed 3+ glycosuria but no ketonuria. Initial plasma insulin and C-peptide levels were inappropriately low for the raised blood glucose level (insulin $2.8 \mathrm{mU} / 1, \mathrm{C}$-peptide $0.17 \mathrm{nmol} / \mathrm{l}$ ), but were within their respective normal ranges by the age of 10 weeks. Serum glucagon level was normal.

The infant was treated with infused insulin from day 1 until day 14 when he was started on subcutaneous insulin. His insulin requirement started to decrease at the age of 6 weeks and insulin was discontinued on day 54 .

Imaging of the pancreas was attempted but no pancreatic tissue was seen on abdominal ultrasound scan at 13 days of age or on contrast CT scan (fig 1) at 19 days of age. However, a repeat abdominal ultrasound scan when the infant was 14 weeks old did show a pancreas of normal size. In the neonatal period, stool chymotrypsin activity was also normal at $13.2 \mathrm{U} / \mathrm{g}$

faeces, indicating that exocrine pancreatic

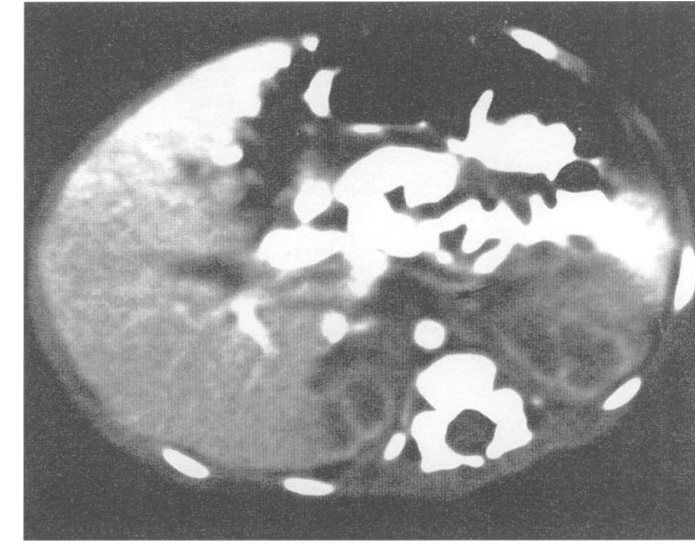

Figure 1 Three millimetre computed tomography of the abdomen between the coeliac axis and superior mesenteric artery, with intravenous contrast; no pancreas was visualised.

tissue was present. At the age of 7 months the infant's weight is $6.2 \mathrm{~kg}$ ( $3 \mathrm{rd}$ centile), length 63 $\mathrm{cm}$ ( $3 \mathrm{rd}$ centile), OFC $43 \mathrm{~cm}$ ( 10 th centile), and his development is normal.

DNA analysis was performed using the CAG repeat for spinocerebellar ataxia type 1 which maps to the region $6 \mathrm{p} 22-23$. The result indicated that the mother is homozygous with a single band of estimated size $208 \mathrm{bp}$, while the father is heterozygous with two bands of estimated sizes 205 and $208 \mathrm{bp}$, respectively. The infant is homozygous for the $205 \mathrm{bp}$ band inherited from his father showing paternal isodisomy at this region (fig 2). PCR was repeated using the dinucleotide repeat markers D6S294, D6S292, D6S975, and D6S305, which map to the regions $6 \mathrm{p} 11-12,6 \mathrm{q} 21,6 \mathrm{q} 23$, and $6 \mathrm{q} 24$ respectively, and paternal isodisomy was confirmed (data not shown).

Transient neonatal diabetes is a rare disorder associated with growth retardation and hyperglycaemia within the first six weeks of life and usually resolves within three to six months. Some affected children develop permanent non-autoimmune diabetes mellitus later in life. ${ }^{47}$ Recent reports of infants with transient neonatal diabetes and UPD $6{ }^{12}$ have led to the hypothesis that an imprinted gene(s) may cause this type of diabetes since three affected infants have each had paternal UPD6. In addition, there are reports of children with paternally inherited 6q22-23 duplications and neonatal diabetes, ${ }^{89}$ one of which also documents 18 similar but maternally derived duplications not associated with transient diabetes.

Our patient had no visible pancreatic tissue present on either an abdominal ultrasound scan or on computed tomography with
Received 22 July 1996 for publication

13 September 1996 


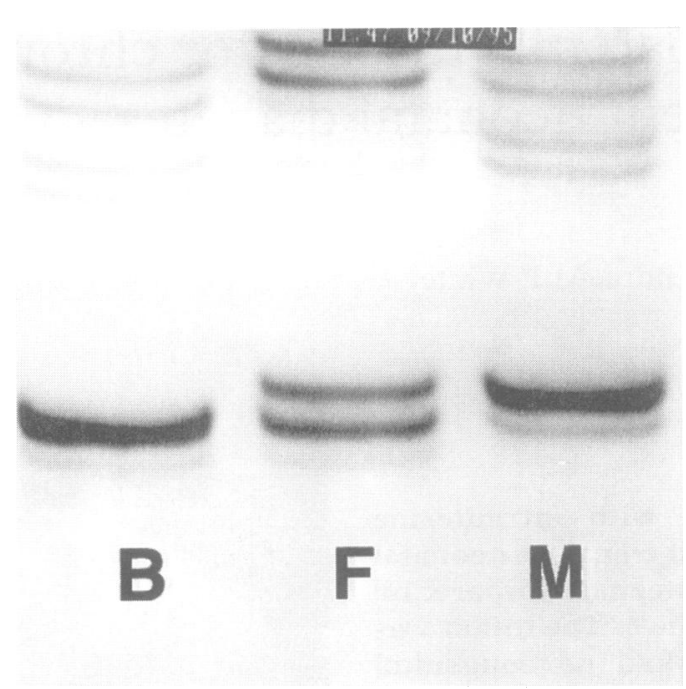

Figure $2 \quad P C R$ gel showing the result of DNA analysis using the spinocerebellar ataxia type $1 C A G$ repeat which maps to 6p22-23. The father $(F)$ is heterozygous with two bands corresponding to $205 \mathrm{bp}$ and $208 \mathrm{bp}$, the mother (M) is homozygous for the $208 \mathrm{bp}$ band, and the baby (B) is homozygous for 205 bp indicating inheritance of only the paternal lower band.

intravenous contrast performed in the neonatal period. However, at the same time there was no evidence of pancreatic malabsorption and glucagon levels were within the normal range, suggesting that both exocrine pancreas and pancreatic alpha cells were functioning normally. Furthermore, a repeat abdominal ultrasound scan performed at 14 weeks indicated a normal pancreas. These confusing results may simply reflect the difficulty in performing imaging studies on growth retarded infants, but we suggest that similar studies are performed on infants who are found to have transient neonatal diabetes and paternal UPD6 to see if this is a consistent finding. The fact that Abramowicz et al observed agenesis of pancreatic beta cells in the patient who had methylmalonic acidaemia and paternal isodisomy 6 may suggest that there is an abnormality in prenatal development of pancreatic tissue in patients with paternal UPD6.

We would like to thank the staff of the Wessex Regional Genetics Laboratory for their help with the DNA analysis and the staff of the Department of Medical Illustration, Yorkhill Hospitals NHS Trust.

1 Temple IK, James RS, Crolla JA, et al. An imprinted gene(s) for diabetes? Nat Genet 1995;9:110-12.

Abramowicz MJ, Andrien M, Dupont E, et al. Isodisomy of chromosome 6 in a newborn with methylmalonic acidaemia and agenesis of the pancreatic beta cells causing diabetes mellitus. $\mathcal{F}$ Clin Invest 1994;94:418-21.

$3 \mathrm{Gentz} \mathrm{JCH}$, Cornblath $M$. Transient diabetes of the newborn. Adv Pediatr 1969;16:345-63.

4 Vanelli M, DeFanti A, Cantoni S, et al. Transient neonatal diabetes mellitus: a relapse after 10 years of complete remission. Acta Diabetol 1994;31:1 16-18.

5 Shield JPH, Baum JD. Is transient neonatal diabetes a risk factor for diabetes later in life? Lancet 1993;341:693.

6 Weimerskirch D, Klein DJ. Recurrence of insulindependent diabetes after transient neonatal diabetes: a dependent diabetes after transient neonatal

7 Gottschalk ME, Schatz DA, Clare-Salzer M, et al. Gottschalk ME, Schatz DA, Clare-Salzer M, et al. toimmunity after transient neonatal diabetes. Diabetes Care 1992;15:1273-6.

8 Temple IK, Gardner RJ, Robinson DO, et al. Further evidence for an imprinted gene for neonatal diabetes localised to chromosome 6q22-q23. Hum Mol Genet 1996;5: 1117-21.

9 Pivnik EK, Qumsieyeh MB, Tharapel AT, et al. Partial duplication of the long arm of chromosome 6: a clinically recognisable syndrome. $\mathcal{F}$ Med Genet 1990;27:523-6. 